\title{
Anticipatory Ethnography: Design Fiction as an Input to Design Ethnography
}

\author{
JOSEPH LINDLEY \\ DHRUV SHARMA \\ ROBERT POTTS \\ HighWire Centre for Doctoral Training, Lancaster University (UK)
}

Here we consider design ethnography, and design fiction. We cast these two approaches, and the design endeavor itself, as forward-looking processes. Exploring the means by which design ethnography and design fiction derive their value reveals the potential for a mutually beneficial symbiosis. Our thesis argues that design ethnography can provide design fiction with the methods required to operationalize the practice in industry contexts. Meanwhile design fiction can provide design ethnographers a novel way of extending the temporal scope of the practice, thus deriving actionable insights that are applicable further into the future.

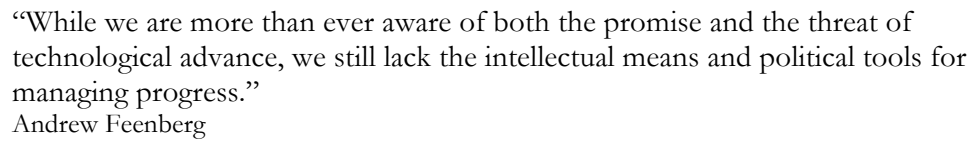

\section{INTRODUCTION}

Design is a success story. Since the industrial revolution, design's influence has spread far and wide into every corner of the world. It is also the success of design as a worldshaping practice that has helped to produce a progressively complex set of problems. Increasingly design and designers are tasked with creating solutions to address the 'wicked"1 implications of the designed world we now inhabit.

All design looks to shape the future, designers have a suite of tools available to help them do this. In this paper we focus on two such tools: design ethnography and design fiction. In the first part of the paper we review our terms of reference: we describe how ethnography has been reconfigured under the banner of design ethnography. Next, we discuss how the practice of design fiction has emerged in recent years, as part of the speculative design movement. In the latter sections of the paper we explain why and how design ethnography and design fiction can work together for mutual benefit. Ultimately we name a new practice: anticipatory ethnography.

\footnotetext{
1 See http://en.wikipedia.org/wiki/Wicked_problem for an overview of wicked problems.
} 
Through defining our terms of reference we aim to expose the key strengths and weaknesses of each practice. We highlight how design ethnography has helped designers understand "use before use" (Redström, 2008 p. 421) therefore abetting design's prospective nature. For design fiction the core strength we focus on is how it derives value from creating fictional worlds. However we also highlight problems within each practice. We argue that design fiction is immature and in need of rigorous methods to facilitate its application in real-world settings and that design ethnography will always have a limited temporal scope so long as it relies on traditional notions of "situated" (Suchman, 1987) observations. We believe design ethnography and design fiction can be configured to work together so that the problems of one are solved by the strengths of the other, and vice versa. ${ }^{2}$

This paper describes, in scholarly terms, how the practice of anticipatory ethnography can be imagined in theory. If we consider the three ways that design and research crossover described by Frayling (1993 p. 5) then this paper should be considered as "research into design". However we believe that the value of this work, for both design and ethnography communities, lies in exploring anticipatory ethnography's use and usefulness in terms of Frayling's "research though design" and "research for design". In our view there is a need to explore practical applications of the theory, so in the final part of the paper we use examples to describe how anticipatory ethnography could be operationalized in a number of different ways.

\section{TERMS OF REFERENCE}

Our proposition is a conflation of design ethnography and design fiction, so it is important to clearly define these practices before attempting to join them together. Through defining the practices, points of connectivity will become visible.

\section{Design}

Design is a process as opposed to a fixed point, a process that is inherently concerned with looking to the future. The act of designing draws together insight from our contextual environment with our knowledge of what has passed. In doing so it reconciles past understandings with present conditions in order to mediate between now and the future. Design transmutes ideas, as they exist in a plurality of possible futures, into specific tangibles that exist in the present. As Simon puts it, "Everyone designs who devises courses of action aimed at changing existing situations into preferred ones" (Simon, 1969 p. 111). Core to our thesis is an appreciation of design's need to operate within the liminal space between 'existing situations' and 'preferred situations'.

"To start with you see the thing in your mind and it doesn't exist on paper and then you start making simple sketches and organizing things and then you start doing layer after layer... it is very much a dialogue." 3

${ }^{2}$ In part this strength/weakness configuration strategy is inspired by Ezio Manzini's work, e.g. Making things happen: Social innovation and Design (2014).

3 Santiago Calatrava, quoted in Engineering design methods: strategies for product design (Cross, 2008). 
Across the many different facets of the design discipline there are many different approaches, each with particular properties, strengths and weaknesses. These approaches are suited to the context in which they operate. Across this spread of approaches there is an equally diverse menagerie of tools employed by designers to understand and bridge the gap between what exists and what is preferable. Design fiction and design ethnography are two of the tools readily available to designers, each with their own quirks and nuances.

\section{Design Ethnography}

Born in the anthropological household, ethnographic practice has been shaped by its engagement with the design family. Since ethnography's inception, as seen in Malinowski's work, the practice has come to be associated with research activities where the intent is to provide a comprehensive and rich account of everyday life and practices, often with the intent of uncovering actionable insights (Segelström and Holmlid, 2012).

However, ethnography's initial encounter with design was marred by "angst", documented in Salvador et al.'s commentary. The observation that, "people who could most benefit from our work in a corporate setting are also the most likely to question its relevance" (Salvador et al., 1999 p. 35-36) hints at the nature of this angst. The authors built a strong case for using ethnographic insights to aid design processes. The use of ethnographic practices in design has come to be known as design ethnography. According to van Dijk, design ethnography is firmly rooted in the design process itself, or "ethnographic qualitative research set within a design context" (2010 p. 1).

Design ethnography needs to operate over shorter timescales than ethnography in social science research, as a result of the rapidity of design life cycles and commercial pressures. To this end it is a 'reconfiguration' of ethnography appropriate for design processes (Crabtree et al., 2012). Ethnography has demonstrated malleability and ductility in response to the hammering it received from the stress of industry and through the demanding relationship with design, and design ethnography continues to evolve, appropriating tools and techniques, adapting them for specific contexts (van Dijk, 2010).

Design ethnography and 'the future' - Design ethnography emphasizes the future (Aiken, 2012) and helps in designing 'use before use'. As a future-shaping endeavor, design per se frequently looks to design ethnography for assistance (Kelley, 2007, Crabtree et al., 2012, Forlano, 2013). Design ethnography though is not without criticism in this area. Dekker et al (2003) quoted by Crabtree et al (2012 p. 170) highlight the temporal limitations of ethnography, "The charge reads that design is all about the future... yet ethnography only focuses on how things are 'here and now' and in turn 'privileges the status quo"'. Design ethnography's ability to transform situated observation into understanding of the near future, while also being hamstrung by its reliance on the present, is key to our formulation of anticipatory ethnography.

The nature of 'situatedness' - Design ethnography derives insights by observing 'situated' (Suchman, 1987) phenomena as they occur in the present (Segelström et al., 2009). Anderson 
points out that ethnography's "emphasis on importance of context for social action" is key (1997 p. 10). This thinking acknowledges the difference between our intentions, actions, and how we renegotiate, interrupt and disrupt plans through our mundane interactions and practices. Context is always a "major part of the study" (Parthasarathy, 2008), so ethnographers are always interested in "situatedness" (Rohlfing et al., 2003).

"Situated activity is not a kind of action... not merely a claim that context is important, but what constitutes the context... To be perceiving the world is to be acting in it... so that what I am perceiving and how I am moving co-determine each other". 4

However, designers can find it difficult to use ethnographically informed "situated action models" to provide design-related conclusions (Nardi, 1996). To address this issue, designers have relied on ethnomethodological variants of ethnography in order to translate insights from situated activities into actionable design insights (Randall et al., 2001, White et al., 2004, Crabtree et al., 2012). Ethnomethodologically informed ethnography warrants legitimacy to the phenomena being observed such "that the description of the situated organization of that activity in its detail makes that real worldly activity mutually intelligible." (White et al., 2004 p. 114). Practically speaking, this lends a layer of believability to the insights that inform design choices because it draws on observations of mundane interaction. It factors in the emotional and practical dimensions of everyday activity, in doing so ethnomethodological approaches help to suspend designers' suspicions.

Design ethnography's ability to produce actionable insights, and the role those insights play in design processes, is of direct relevance to anticipatory ethnography. We contend that design ethnography produces insights that help designers understand the future, however it follows that those insights can only be applicable to relatively near futures so long as they're derived from observations of the present. The tie to the present is a function of design ethnography's inseparable relationship with situated observations.

\section{Design Fiction}

Although all design flirts with the future, a group of design practices that we collectively refer to as 'speculative design' have a more explicit relationship with the future and are the product of a wider 'speculative turn' in the design world. ${ }^{5}$ The various approaches united under the banner of speculative design include critical design, futurescaping, design futures and design fiction (Raford, 2012). Traditional design practices reflect Simon's (Simon, 1969) vision of design as a tool for getting from existing to preferred situations through incremental steps "up and to the right" (Bleecker, 2009). This traditional model of design invariably arrives at a singular 'preferable' outcome. Speculative design is distinct in that it strives to open up a discursive space that is underwritten by the

\footnotetext{
${ }^{4}$ Quotation from: Clancey J. N. 1993 p. 95. Situated action: A neuropsychological interpretation response to Vera and Simon. Cognitive Science, 17(1), 87-116.

${ }_{5}^{5}$ Although somewhat intangible the 'speculative turn' is hinted at by the rise of speculative design (see Dunne \& Raby's Speculative Everything, 2013) and referred to elsewhere by influential writers, e.g. http://www.wired.com/2011/12/design-fiction-digital-creativity-special-issue-on-design-fictions /
} 
unavoidable plurality of the future. As Dunne \& Raby put it "the idea is not to show how things will be but to open up a space for discussion” (2013 p. 51).

Where Carlson's (2006) model sees design as a process constructed by both idea, and a resultant artifact, speculative design approaches are almost entirely focused on the idea, the plurality of the idea, and the associated connotations of that thinking. This is not to say that speculative design doesn't involve the making of things, as it does, however these artifacts are considered as provocations or stimuli rather than preferable outcomes in their own right.

The particular speculative design approach we're interested with is design fiction. Design fiction looks to achieve the goals of speculative design by designing with fiction. To be clear, the use of the word fiction does not refer to designs that are 'made up' or unreal (although they may be). Rather, design fiction refers to designing with stories, or within the world of a story. Creating a believable and relatable story world allows design fictions to first represent and then explore the nuances and 'mundanity' of future circumstances. A healthy design fiction 'situates' the viewer in a prospective future so they can envision it in a meaningful way.

The 'diegetic prototype' - Futurologist Bruce Sterling defines design fiction as "the intentional use of diegetic prototypes to suspend disbelief in the future" in an interview with slate.com ${ }^{6}$. We will unpack this definition in order to highlight what design fiction is and what its specific value proposition is.

First of all, let's consider prototyping. Prototyping is a key part of many design processes, often employed by designers as an 'internal stimulus' to a project. It is an incredibly powerful tool, allowing designers and design teams to understand how the product of their divergent, creative, or "designerly" ways of knowing (Cross, 2008) might manifest themselves in a finished product. Tom Kelley calls prototyping the "shorthand of design" (2001) allowing designers to 'play' with ideas before committing to one. If we refer back to our vision of design as an inherently forward-looking process, then one of the roles that the physical prototypes play is to allow us to go beyond mental models of the future. By prototyping, in the traditional sense, we can touch, feel, and interact with possible futures. In many ways prototypes allow designers to have 'situated' interactions with concepts.

But what is a diegetic prototype? As alluded to above, the fiction element of design fiction refers to stories, it is from this foundation in stories that the term diegesis comes into play. Diegesis is the 'world of the story'. Any story's diegesis is constructed from anything that exists within that particular story world. So, if the characters in the story can hear it, touch it, or see it, then it is likely to be diegetic. For example the orchestral scores added over the top of dramatic battle scenes in Saving Private Ryan are non-diegetic because the characters cannot hear the music. However, the men on the beaches, the crashing waves, the sounds of the guns; these are all diegetic. Anything that is diegetic may be considered 'real' in

${ }^{6}$ Quotation from

http://www.slate.com/blogs/future_tense/2012/03/02/bruce_sterling_on_design_fictions_.html 
terms of the world of the story and everything that is diegetic is contextually consistent with every other element of that diegesis?.

The concept of the 'diegetic prototype' then, is anything that is being prototyped within the diegesis of a story. Leveraging the value of prototyping, but doing so in a fictional world, diegetic prototypes don't need to exist in reality and must only be consistent with their own diegesis. As such virtually all design constraints are removed. One such constraint that is negated by using diegetic prototypes is that of time, hence why design fiction is particularly compelling for speculative design. Diegetic prototypes can transcend the time horizon of the present and begin to address McLuhan and Fiore's contention that we "attach ourselves to objects, to the flavor of the most recent past. We look at the present in the rear view mirror" (1967 p. 74-75). Using diegetic prototypes, packaged inside design fiction artifacts, we arrive at a compelling approach to design practice, free from temporal constraints.

Design fictions are usually manifested as films, which is not surprising when you trace the roots of diegetic prototyping and design fiction back to sci-fi film and television (Kirby, 2010). However, increasingly design fictions are moving beyond the medium of film. ${ }^{8}$ Nonfilmic approaches may well enrich design fiction's potential relevance to anticipatory ethnography, however that discussion is beyond the scope of this paper, and for the sake of simplicity we will continue with the assumption that these diegeses are the story worlds created inside film-based design fiction artifacts.

The diegetic prototype is not a new thing; traces of diegetic prototypes exist within DaVinci's inventions, in works of fiction from Jules Verne's The Time Machine to E.M Forster's The Machine Stop, right through to comic books like Stan Lee's X-men and television series' such as Star Trek. In almost any science fiction work some form of diegetic prototype exists. However it has taken the huge acceleration of change resultant from times of modernity to actually show us the persuasive character of diegetic prototypes to predict, and arguably shape, new sociotechnical directions. This process, at first delivered through science fiction novels, series and films is beginning to happen before our eyes, powered by the networked information age that we live in (Lanier, 2014).

Noting this fascinating phenomenon, David Kirby posited the value of using diegetic prototypes as a way of understanding and generating insights from fiction that can be applied directly to science: "Movies have provided many film-makers and scientists with the opportunity to create diegetic prototypes establishing the necessity, viability and minimization of risk associated with space travel" (2010 p. 65). Embracing Kirby's idea, the design fiction movement has taken it upon itself to do precisely that. Returning to Sterling's definition of design fiction, a central point is that designers are now using diegetic prototypes intentionally. Whereas in examples from literature, film and comics, diegetic prototyping occurs as a byproduct of the storytelling and entertainment endeavor, designers

\footnotetext{
7 Film studies scholar Stephen DaVega's video, 'Diegetic Non-diegetic', gives a more in-depth discussion of diegesis https://www.youtube.com/watch?v=juVb1SDHWrk

8 For example: Superflux's $5^{\text {th }}$ Dimensional Camera (http://www.superflux.in/work/5th-dimensionalcamera), Winning Formula (http://winningformula.nearfuturelaboratory.com/) and an interview with Nicholas Nova (http://savageminds.org/2014/02/14/anthropology-design-nicolas-nova/).
} 
and practitioners of design fiction now are mobilizing diegetic prototypes intentionally for the purposes of informing design processes and projects.

Although the phenomenon that is diegetic prototyping has many exemplars in science fiction, which appear to demonstrate its value, simply applying it to design problems is not straightforward. Julian Bleecker recently commented, almost exactly four years after his influential essay on the subject, that "I don't think we've figured it out" and "studying it, understanding it and trying to devise some of the principles - of what we're calling design fiction - is what we're trying to do" (2013). This raises the question, if design fiction is a tool to explore the future then it is a means, but to what end? Design fiction needs theories and methods from which designers can operationalize the powerful phenomenon of diegetic prototyping so the resulting insights can become part of real world design challenges. This paper paves the way for one such method.

\section{JOINING THE DOTS}

So far we have introduced the constructs that are necessary in order to theoretically build the practice we're calling anticipatory ethnography. In this section we will explicitly describe how the relevant properties of the two constructs (properties that we refer to as 'dots') may be joined together (as with 'join the dots' picture books) thus allowing the full 'outline' of anticipatory ethnography to emerge. Our dots come under three headings, explained below.

\section{Temporal Constraint}

We have posited that all design processes attempt to move from existing situations to preferred situations. Design fictions are interested in the preferable too, but by virtue of the diegetic prototype are temporally disinhibited when compared to traditional design. This quality is one pillar supporting our vision of anticipatory ethnography.

Design ethnography's primary goal is to explore the present with a view to producing actionable insights that will inform the near future. Although not a clear-cut debate, our position is that the further into the future insights derived ethnographically try to look, the weaker the 'signals from the present' will be. In other words if a design team attempts to understand the 'preferability' of futures based upon observations of now, there is a limit as to how far design ethnography can look: design ethnography is temporally constrained.

Our contention is that these two facets of each practice can be configured to work together. So if we accept that design ethnography is temporally constrained, and then align that position with the understanding that design fiction is not, then it would appear logical to assume that design fiction may well be a viable means of temporally unbinding design ethnography. Conversely, if such a formulation were possible it would simultaneously serve design fiction's need for firmer methods and modes of analysis.

\section{Suspending Disbelief}

Design fiction uses diegesis, in the words of Bruce Sterling, to "suspend disbelief in the future". The implication of this phrase is that the diegesis of any particular design fiction 
should describe the future in believable terms i.e., in terms that are suitably mundane as to allow the audience to become 'situated' in the diegetic reality of the design fiction. In this way, diegesis serves to 'situate via proxy'.

The related design ethnography dot is contained within the concept of situatedness. The way in which we interpret and understand the world isn't just about activity, it isn't just about context, but it is an amalgam built from both together (Clancey, 1993). As applied to design problems this can be seen as ethnographic insights becoming more believable when backed up by context. This allows insights to become 'mutually intelligible' to both ethnographers and designers, thus suspending the disbelief of the design team.

We posit that the use of diegesis and situated observations both add value by providing a means to suspend disbelief. The difference is that design fiction does it in the future based upon fictional scenarios, whereas design ethnography does so based upon observations of the present. Although there is this temporal contrast, in most other ways we believe the concepts are interchangeable.

It would be fair to say that design ethnography's relationship with situatedness, is in effect, the act of studying the 'diegesis of reality'. In other words a conflation of context, process, and action that come together to form a believable story. We therefore believe that both design fiction and design ethnography derive their value in the same way.

\section{Insightful Dialogue with the Future}

We argue that the insights produced by design ethnographies are in isolation not immediately useful entities. Instead, it's through a dialogue about these insights that true meaning emerges, which can then be 'actioned' by designers. Because design ethnography is a relatively established field, it has developed methods to not only use situated observations to produce actionable insights, but also to facilitate interactions between designers and researchers about those insights. These interactions exist within a 'discursive space' from within which a meaningful dialogue about a near future can be had. The nature of this discursive space is akin to the properties of design fiction artifacts. 


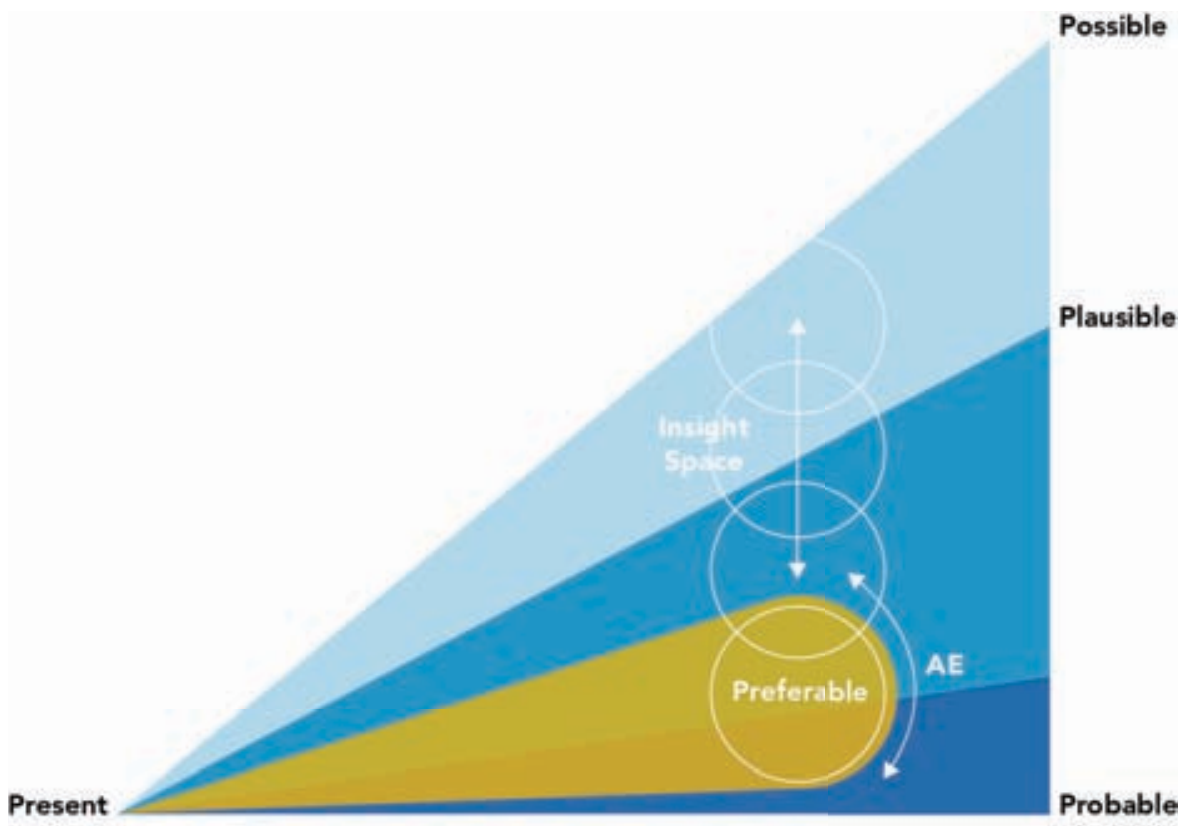

The diagram shows how anticipatory ethnography allows an actuation of the 'band of preferability' that sits atop the spectrum of possible futures, thus facilitating insightful dialogue about the future. This diagram is adapted from Stuart Candy's Cone of Possibility Space (2010) and Dunne \& Raby's PPPP

(Speculative Everything, 2013 p. 5).

To reiterate our position on speculative design and design fiction: these practices do not endeavor to didactically indicate singular visions of the future, but rather to forge an environment conducive to conversations. These conversations are intentionally questioning and ultimately want to arrive at new questions which in their own right will help to understand where preferable outcomes sit on a spectrum of probable, plausible, or possible futures. So as with design ethnography the underlying value of design fiction is the insightful dialogue about the future, and that dialogue is an emergent property of the discursive space.

\section{In Summary}

It is by defining this parity between these various properties of design fiction and design ethnography that we believe creates the theoretical space to intellectually envision anticipatory ethnography. 


\begin{tabular}{|l|l|l|l|}
\hline & \multicolumn{1}{|c|}{ Design Ethnography } & \multicolumn{1}{c|}{ Design Fiction } & Anticipatory Ethnography \\
\hline Temporal Dimension & Based on the present & Unrestrained & Inherited from design fiction \\
\hline Source of Context & Situatedness & Diegesis & Diegetically situated \\
\hline Ouputs & Actionable insights & Discursive space & Insight space \\
\hline Methods & Well developed & Nascent & Proposed \\
\hline
\end{tabular}

\section{Summary of the joined properties alongside the corresponding emergent properties of anticipatory ethnography.}

\section{COLORING BETWEEN THE DOTS}

Having explored various theoretical frames for why anticipatory ethnography is a theoretically viable practice, here we explore some practical ways of enacting the theory. At this stage we cannot make an incisive argument for the 'best' way of conducting anticipatory ethnographies. Empirical work is certainly needed to address questions such as at what stage of design processes should anticipatory ethnography take place, and how to configure the idea for different design contexts? Rather than suggest we 'know' how to proceed we've tried to paint a picture of a fertile landscape that is ripe for development and here we present examples to clarify the potential of that landscape, beginning to make it tangible. These 'modes' of doing anticipatory ethnography may be used as blueprints for further exploration and as seed ideas for those looking to expand upon or test the concept.

\section{Examples of Anticipatory Ethnography in Action}

We suggest looking at design fiction prototypes as a painting (in harmony with our 'joining the dots' metaphor). There are three parts to this metaphorical painting, corresponding to three approaches to anticipatory ethnography:

- Studying the process of creating a design fiction (ethnography of the paint, brushes, and making of a painting).

- Studying how an audience interacts with or perceives a design fiction (ethnography of people viewing the painting).

- $\quad$ Studying the content of a design fiction (ethnography of the painting itself).

We have equated the 2013 film "Her" directed by Spike Jonze, to a design fiction for the sake of our examples. A Hollywood movie, sitting within the sci-fi, drama and romance genres, Her also exhibits properties that qualify it as a design fiction: emphasis on the future and an affecting diegesis together give the film the potential to suspend disbelief. We acknowledge that the amount of resources dedicated to making Her (a budget in excess of $\$ 20 \mathrm{~m}$, for instance) are not readily available to the majority of design projects, however this 
doesn't preclude the film from being an efficient vehicle to articulate how anticipatory ethnography may be enacted?.

\section{Studying the Process of Creating a Design Fiction}

In terms of our metaphor we describe this mode as doing an 'ethnography of the paint, brushes, and making of the painting'. In practical terms we suggest employing elements of design ethnography's toolkit and applying them to a study of the creative team behind design fiction productions. Writers, directors and actors can become very close to projects. Can this proximity allow them to become 'situated in the diegesis'?

Spike Jonze purportedly realized while producing the film that "[Her] isn't a movie about technology. It's a movie about people” (Vanhemert, 2014), hinting at Jonze's 'interior' relationship with the diegesis of the film. In another interview about the film Jonze says "When something felt weird, when Joaquin was uncomfortable with something, I knew it meant there was some place I had cheated or hadn't thought through or hadn't gone deep enough. His flinch is always worth listening to." (Harris, 2013). The second observation indicates that the actor (Joaquin) was so 'situated' within the diegesis that the director used the actor's insight to sense-check his production decisions. Together these sentiments suggest that the process of making a design fiction may be a suitable site for anticipatory ethnography.

\section{Studying How an Audience Interacts With or Perceives a Design Fiction}

In this mode of anticipatory ethnography we suggest employing the concepts of audience ethnography (La Pastina, 2005) or in terms of our metaphor 'an ethnography of the people viewing the painting'. Two possible approaches are by using the 'afterglow'10 or through more structured techniques such as diary studies, generating scenarios, task-focused scenarios or accompanied viewing with audience members (Quirk et al., 2009).

We want to highlight that the audience can be considered situated via proxy, within the story world of a design fiction. This supposition pivots around the strength of the diegesis; it must be believable and relatable to the individual realities of the audience. Referring back to $H e r$, the production team went to considerable lengths to make the fictional future depicted in the film appear familiar, even mundane. The team strived to make the technological parts of the film's diegesis easy to follow and not intrusive. In the words of the production designer this served to "undesign the design" (Vanhemert, 2014), or said differently to allow an effortless suspension of disbelief. This 'undesign', if done well, situates the audience vicariously within the world of the film. Assuming the audience is situated in this way, we can infer that they also harbor the knowledge necessary to glean ethnographic insights from them.

\footnotetext{
9 Wired's article, Why Her Will Dominate UI Design Even More Than Minority Report (http://www.wired.com/2014/01/will-influential-ui-design-minority-report/) hints at Her's design fiction qualities.

${ }^{10}$ Here we refer to observations of audiences immediately after they've engaged with a design fiction artifact.
} 


\section{Studying the content of a design fiction}

This final mode of anticipatory ethnography we believe to be the most attractive both theoretically and practically speaking. In terms of our metaphorical view of anticipatory ethnography this can be considered an 'ethnography of the painting itself'. Where our first two modes require working with either the production team behind a design fiction film or the audience interacting with a design fiction film, in this approach the ethnographer directly engages with the artifact. This mode could be conducted on any design fiction artifact, whether the researcher was involved with its production or not.

Very simply put the idea is to immerse oneself in a design fiction with a design ethnography 'hat' on and gathering field notes that pertain to the content of the film. This hinges on the ability of the diegesis to conjure the effect of situatedness by in order for this mode to work properly. However in contrast to the other modes, allowing the ethnographer to directly engage with the diegesis makes the proposition less challenging.

Film reviews of Her exemplify the richness of the film's story and appear to contain insights that we frame as being 'sub-ethnographic'. For instance, in his analysis Scott Myers "goes into the movie" (2014) and provides a glimpse of his raw observations that bear an uncanny resemblance to an ethnographer's notes. Jason Farago has gone beyond raw observation and towards insights, "You can ask, too, about the value of Theodore's love for Samantha... not only as legitimate but as morally improving" (2013). In this mode the ethnographer becomes immersed in the design fiction such that they are 'diegetically situated' and the methods of design ethnography become immediately relevant.

\section{Reflections on the Finished Painting}

These examples allow us to reveal how the theoretical relationship between design ethnography and design fiction introduced in our 'joining the dots' section can be brought out of theory toward practical applications, thus we hope to build confidence in the proposition. The crosscutting principles of these examples is how design ethnography's reliance on rich context (Geertz, 1994) is comparable to design fiction's reliance on diegesis. It follows that anticipatory ethnography, therefore, relies on diegesis. Beyond reliance it is also true that a design fiction can only really be considered a suitable site for anticipatory ethnography if its diegesis is a truly affecting one.

Our objective in framing anticipatory ethnography in this way (to define our terms of reference, then to explain how the 'dots' can be joined, and finally how to color the space between these dots) is to leave the reader inspired by the concept alone, but also to provide some clarity around how it may be done in practice.

\section{CONCLUDING REMARKS}

In this paper we have discussed how design ethnography and design fiction are tools to aid and abet design processes. By reviewing these practices, we have established that they have common goals and furthermore there are some similarities in the ways that they work 
toward these goals. We hypothesize that these similar properties can be linked in a way that is mutually beneficial to both endeavors. Once these properties are connected, anticipatory ethnography emerges as a nascent practice.

Anticipatory ethnography addresses design fiction's need for methods, capitalizing on design ethnography's richer methodological history. Building on an ability to adapt and reconfigure itself there are benefits for design ethnography too. By subverting traditional notions of situated observation design ethnography achieves a new temporal liberty.

In light of the pace of change in the $21^{\text {st }}$ century, along with the increasingly vivid

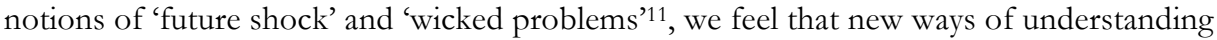
and preempting the future are more starkly compelling than ever before. The vastness of the problem space that we're concerned with requires a suitably bold response, by presenting our position on anticipatory ethnography we have taken steps towards such a response.

In order to see the vision become a reality further research is needed. We call upon the design fiction and design ethnography communities to come together in order to develop these ideas, extend the concept, and demonstrate the merits, shortcomings, relevance and scope of this work, through empirical investigations.

Joseph Lindley is a PhD researcher at the HighWire Centre for Doctoral Training at Lancaster University (UK). He has a range of professional experience working as a technologist, artist, musician and photographer. His current research is in the field of speculative design and design fiction. joseph.lindley@gmail.com

Dhruv Sharma is a PhD researcher at the HighWire Centre for Doctoral Training at Lancaster University (UK). He is an anthropologist and a design ethnographer with design research experience in the industry as well as academia. dhruvsharma101@gmail.com

Robert Potts is a HighWire $\mathrm{PhD}$ at Lancaster University. Trained in visual communication, he teaches and researches design. As a creative director, he consults on design projects and makes innovative films. His research uses narrative to explore collaboration across boundaries in creative and critical environments.r.potts@lancaster.ac.uk

\section{NOTES}

Acknowledgments - This work was produced at the HighWire Centre for Doctoral Training, funded under the RCUK Digital Economy Programme (Grant Reference EP/G037582/1).

\section{REFERENCES CITED}

Aiken, J. O.

11 Future Shock is a book by Alvin Toffler (1970) discussing the effects of rapid change on societies and individuals. The concept of the 'wicked' problem describes interlinked, contradictory, and shifting requirements (see http://en.wikipedia.org/wiki/Wicked_problem). 
2012 Integrating Organizational and Design Perspectives to Address Challenges of Renewal: A case study of NASA's post-shuttle workforce transition. Ethnographic Praxis in Industry Conference Proceedings. Wiley Online Library.

Anderson, Bob

1997 Work, Ethnography and System Design, Cambridge, Rank Xerox Research Centre.

Bleecker, Julian

2009 Design Fiction: A short essay on design, science, fact and fiction. Near Future Laboratory.

Bleecker, Julian

2013 A Design Fiction Evening with the Near Future Laboratory (Timecode 1:11:34) [Online]. Available: http://vimeo.com/84826827 [Accessed 11 August 2014].

Carlson, David

2006 Design (in) the future [Online]. Available: http://davidreport.com/the-report/issue-32006-design-in-the-futu/ [Accessed 10 June 2014].

Clancey, William J.

1993 Situated action: A neuropsychological interpretation response to Vera and Simon. Cognitive Science, 17, 87-116.

Crabtree, Andrew, Rouncefield, Mark, et al.

2012 Doing Design Ethnography, London, Springer-Verlag.

Cross, Nigel

2008 Engineering design methods: strategies for product design, John Wiley \& Sons.

Dekker, Sidney W. A., Nyce, James M., et al.

2003 From contextual inquiry to designable futures: What do we need to get there? Intelligent Systems, IEEE, 18, 74-77.

Dunne, Anthony \& Raby, Fiona

2013 Speculative Everything: Design, Fiction, and Social Dreaming, MIT Press.

Farago, Jason

2013 'Her' is the Scariest Movie of 2013 [Online]. Available: http://www.newrepublic.com/article/116063/spike-jonzes-her-scariest-movie2013 [Accessed 11 August 2014].

Forlano, Laura

2013 Ethnographies from the Future: What can ethnographers learn from science fiction and speculative design? [Online]. Available: 
http://ethnographymatters.net/blog/2013/09/26/ethnographies-from-the-futurewhat-can-ethnographers-learn-from-science-fiction-and-speculative-design/ [Accessed 13 March 2014].

Geertz, Clifford

1994 Thick description: Toward an interpretive theory of culture. Readings in the philosophy of social science, 213-231.

Harris, Mark

2013 Him and Her: How Spike Jonze Made the Weirdest, Most Timely Romance of the Year [Online]. Available: http://www.vulture.com/2013/10/spike-jonze-on-makingher.html [Accessed 11 August 2014].

Kelley, Tom

2007 The art of innovation: lessons in creativity from IDEO, America's leading design firm, Random House LLC.

Kelly, Tom

2001 Prototyping is the Shorthand of Design. Design Management Journal, 12, 1-9.

Kirby, David

2010 The Future is Now Diegetic Prototypes and the Role of Popular Films in Generating Real-world Technological Development. Social Studies of Science, 40, 4170.

La Pastina, Antonio C

2005 Audience Ethnographies. Media anthropology, 139.

Lanier, Jaron

2014 Who owns the future?, Simon and Schuster.

McLuhan, Marshall \& Fiore, Quentin

1967 The medium is the massage: An inventory of effects, Penguin.

Myers, Scott

2014 Movie Analysis: "Her" [Online]. Available:

http://gointothestory.blcklst.com/2014/01/movie-analysis-her.html [Accessed 11 August 2014].

Nardi, Bonnie A.

1996 Studying context: A comparison of activity theory, situated action models, and distributed cognition. Context and consciousness: Activity theory and buman-computer interaction, 69-102. 
Parthasarathy, Balaji

2008 The ethnographic case study approach [Online]. Technology \& Social Change Group, University of Washington Available:

http://www.globalimpactstudy.org/2008/07/the-ethnographic-case-studyapproach/ [Accessed 11 June 2014].

Quirk, Rachel, Olver, Martin, et al.

2009 The Guide to Researching Audiences, JISC.

Raford, Noah

2012 From Design Fiction to Experiential Futures. In: Currey, Andrew (ed.) In The Future of Futures. Houston, TX, USA: Association of Professional Futurists.

Randall, Dave, Marr, Liz, et al.

2001 Ethnography, ethnomethodology and interaction analysis. Ethnographic Studies, 6, $31-43$.

Redström, Johan

2008 RE: Definitions of use. Design Studies, 29, 410-423.

Rohlfing, Katharina J., Rehm, Matthias, et al.

2003 Situatedness: The interplay between context (s) and situation. Journal of cognition and culture, 3, 132-156.

Salvador, Tony, Bell, Genevieve, et al.

1999 Design ethnography. Design Management Journal (Former Series), 10, 35-41.

Segelström, Fabian \& Holmlid, Stefan

2012 One Case, Three Ethnographic Styles: Exploring different ethnographic approaches to the same broad brief. Ethnographic Praxis in Industry Conference Proceedings. Wiley Online Library.

Segelström, Fabian, Raijmakers, Bas, et al.

2009 Thinking and doing ethnography in service design. LASDR, Rigor and Relevance in Design. Seoul.

Simon, Herbert Alexander

1969 The sciences of the artificial, MIT press.

Suchman, Lucy A.

1987 Plans and situated actions: the problem of human-machine communication, Cambridge university press.

van Dijk, Geke 
2010 Design ethnography: Taking inspiration from everyday life [Online]. Available: http://www.stby.eu/wp/wp-content/uploads/2011/01/designet.pdf [Accessed 8 June 2014].

Vanhemert, Kyle

2014 Why Her Will Dominate UI Design Even More Than Minority Report [Online]. Available: http://www.wired.com/2014/01/will-influential-ui-design-minority-report/ [Accessed 11 August 2014].

White, Marian Iszatt, Kelly, Simon, et al.

2004 'Following The Leader': Ethnography, Ethnomethodology and Educational Research. 